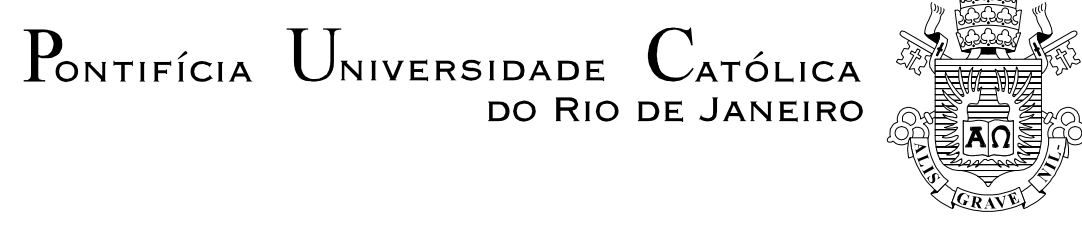

Ecatherina Aleixo Brasileiro Borges

\title{
A Linguagem dos Objetos na Habitação Contemporânea: a sala de "estares"
}

\section{Dissertação de Mestrado}

Dissertação apresentada como requisito parcial para obtenção do grau de Mestre pelo Programa de Pósgraduação em Design do Departamento de Artes \& Design da PUC-Rio.

Orientadora: Profa. Vera Lucia Moreira dos Santos Nojima 


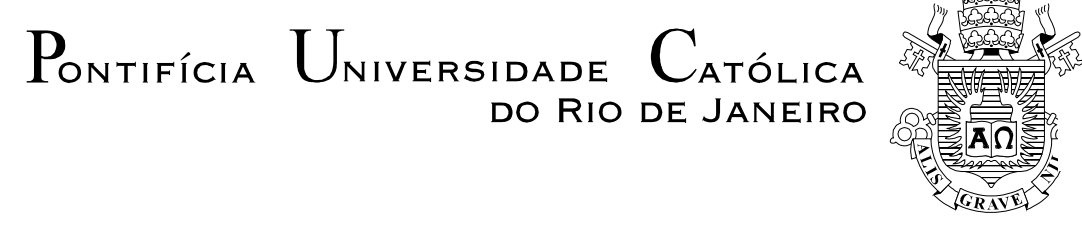

Ecatherina Aleixo Brasileiro Borges

\section{A Linguagem dos Objetos na Habitação Contemporânea: a sala de "estares"}

Dissertação apresentada como requisito parcial para obtenção do grau de Mestre pelo Programa de PósGraduação em Design do Departamento de Artes \& Design do Centro de Teologia e Ciências Humanas. Aprovada pela Comissão Examinadora abaixo assinada.

Profa. Dra. Vera Lucia Moreira dos Santos Nojima

Presidente/Orientadora - PUC-Rio

Profa. Dra. Angeluccia Bernardes Habert Membro - PUC-Rio

Prof. Dr. Alberto Cipiniuk Membro - PUC-Rio

Prof. Paulo Fernando Carneiro de Andrade

Coordenador Setorial do Centro de Teologia e Ciências Humanas - PUC-Rio

Rio de Janeiro, de de 
Todos os direitos reservados. É proibida a reprodução total ou parcial do trabalho sem autorização da universidade, da autora e da orientadora.

\section{Ecatherina Aleixo Brasileiro Borges}

Graduou-se em Arquitetura e Urbanismo na Universidade Federal da Bahia / Bahia em 1997. Cursou especialização em Design de Produto na Universidade do Estado da Bahia PósDesign / Bahia em 2001. Profissional Autônoma na área de Arquitetura de Edificações, Arquitetura de Interiores e Design de Mobiliário.

Ficha catalográfica

Borges, Ecatherina Aleixo Brasileiro

A linguagem dos objetos na habitação contemporânea: a sala de "estares" / Ecatherina Aleixo Brasileiro Borges; orientadora: Vera Lucia Moreira dos Santos Nojima. - Rio de Janeiro : PUC-Rio, Departamento de Artes \& Design, 2006.

178 f. ; $30 \mathrm{~cm}$

Dissertação (mestrado) - Pontifícia Universidade Católica do Rio de Janeiro, Departamento de Artes \& Design

Inclui bibliografia

1. Artes - Teses. 2. Significação dos objetos. 3. Design de interiores. 4. Habitação contemporânea. I. Nojima, Vera Lucia Moreira dos Santos. II. Pontifícia Universidade Católica do Rio de Janeiro. Departamento de Artes \& Design. III. Título.

CDD: 700 


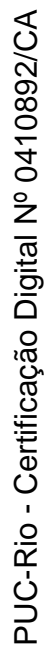

Aos meus pais e marido 


\section{Agradecimentos}

Agradeço a professora Vera Nojima pelo carinho, respeito e confiança em minha proposta de trabalho.

Agradeço a todos os meus professores das matérias cursadas, em especial para o professor Alberto Cipiniuk, pelas conversas tão construtivas dentro e fora de sala de aula.

Aos membros da banca, Alberto Cipiniuk e Angeluccia Habert, pela bela receptividade ao convite.

Aos meus amigos. Por eles.

Aos entrevistados pela confiança e disponibilidade.

Agradeço ao pessoal do Departamento de Artes pela cordialidade e atenção.

Aos meus colegas do programa de Pós-Graduação em design da PUC-Rio.

Aos meus pais, Nanja e Antônio Brasileiro, pela minha formação tão cuidadosa.

Ao meu marido, Silvio Tendler, por todo bem estar que me proporcionou nesta jornada e pela permissão de acesso a todo material de entrevista do professor Milton Santos.

A Ana Salac, minha doce estagiária, sem ela seria impossível organizar todo o vasto material desta pesquisa. 


\section{Resumo}

Borges, Ecatherina Aleixo Brasileiro; Nojima, Vera Lucia Moreira dos Santos Nojima. A Linguagem dos Objetos na Habitação Contemporânea: a sala de “estares”. Rio de Janeiro, 2006. 178p. Dissertação de Mestrado - Departamento de Artes \& Design, Pontifícia Universidade Católica do Rio de Janeiro.

Depois da explosão demográfica das grandes cidades, da diminuição dos espaços internos das moradias e da hostilização dos espaços públicos, pode-se estar vivenciando o esvaziamento ou limitação de valor simbólico dos objetos industrializados para residência e uma possível preponderância de valores inócuos, tendendo ao historicismo nostálgico ou decorativismo falacioso. Esvaziamento provocado pela massificação da indústria, suportada quase exclusivamente pela publicidade, em detrimento de uma simbologia verdadeira e própria de um tempo ou uma região. Como pode então o designer elaborar um ambiente que atenda às subjetividades do indivíduo? Dispor várias peças em um ambiente é lidar com um momento de verdade íntima, constituído por uma subjetividade sem efemeridades e modismos. Na busca de 'fatos' e 'impressões', foram realizadas, em quatro capitais brasileiras - Rio de Janeiro, São Paulo, Salvador e Recife, entrevistas com pessoas que se propuseram decorar a sala de estar de suas residências e esses espaços foram analisados. Foram escolhidas, como perfil de entrevistado, pessoas de poder aquisitivo padrão 'B' e 'C' cujas salas medissem entre 18 e $35 \mathrm{~m}^{2}$. Verificou-se o alcance da significação dos objetos no percurso pelas instâncias sociais, da concepção ao momento de uso. Das entrevistas, foram identificados parâmetros de valores norteadores na construção dessa significação. Foi verificado também como se estabeleceu a relação entre o discurso subjetivo dos desejos humanos e a matéria-artefato na ambientação contemporânea. Este trabalho proporcionou uma reflexão sobre o papel do design na elaboração de ambientes que atendam às necessidades elementares ou subjetividades do indivíduo, colaborando, assim, para sua saúde física e mental.

\section{Palavras-chave}

Significação dos objetos, design de interiores, habitação contemporânea. 


\section{Abstract}

Borges, Ecatherina Aleixo Brasileiro; Nojima, Vera Lucia Moreira dos Santos. The language of the contemporary habitation's objects: The “living-room of feelings". Rio de Janeiro, 2006. 178p. MSc. Dissertation -Arts \& Design Department, Pontifícia Universidade Católica do Rio de Janeiro.

After the demographic explosion of the big cities, reduction of the internal spaces of the housings and hostilization of the public spaces, we can be living the emptyning or limitation of symbolic value of industrialized objects for residence and a possible superiority of inoccuous values, tending to the nostalgic historicism or fallacious decorativism. Emptyness provoked by massification of the industry, supported almost exclusively for the advertising, in detriment of a true and proper symbology of a time or a region. Thus, how can a designer elaborate an environment that attends the individual subjectivities? To make use or arrange furniture and objects in our room is to deal with a moment of close truth, without efemerities and modisms. In the search of 'facts' and 'impressions' interviews were elaborated in four Brazilian capitals: Rio de Janeiro, São Paulo, Salvador and Recife. Those interviews were made with people who decorated their living room by their own. These spaces had also been analyzed. It was chosen as a standard profile interviewed people of purchasing power levels ' $\mathrm{B}$ ' and ' $\mathrm{C}$ ', whose rooms measured between 18 to $35 \mathrm{~m}^{2}$. The reach of the meaning of objects in the passage for the social instances was verified, from the conception to the moment of use. From the interviews parameters of reference values were identified, on the construction of this signification. It was also verified how was established the relations between the subjective speech of the human desires and the substance-device in the contemporary ambientation. This work provided a reflection on the role of design in the environment elaboration that takes care of to the elementary necessities or subjectivities of the individual, collaborating, thus, for its physical and mental health.

\section{Keywords}

Object's meaning, interior's design, habitation contemporary. 


\section{Sumário}

1. Prólogo 13

2. Introdução 17

3. Explanações acerca do conteúdo de uma sala 28

4. Momentos de significação 34

4.1. A sala na estrutura social atual 37

4.1.1. Concepção 39

4.1.2. Produção 47

4.1.3. Distribuição

4.1.4. Consumo 53

4.2. Casa Claudia: uma visão da história 62

5. A pesquisa $\quad 90$

5.1. Problema 90

5.2. Hipóteses $\quad 91$

5.3. Objeto da pesquisa $\quad 92$

5.4. Variáveis 92

5.5. Objetivo Geral 94

5.6. Objetivos Específicos $\quad 94$

5.7. Justificativa $\quad 94$

5.8. Corpus da pesquisa $\quad 94$

5.9. Caracterização da pesquisa 95

5.10. Delineamentos 96

6. Resultados 105

6.1. Bloco I: As questões 105

6.1.1. Dificuldade de definição do que é um objeto de Design 105

6.1.2. Função e uso 107

6.1.3. O funcional x o simbólico: o confronto 111

6.1.4. A sala da fotografia 116

6.1.5. Para além da Combinação 119

6.1.6. Modernismo, modernidade e atualidade versus gosto íntimo 122

6.1.7. Identidade 124

6.1.8. Inserção em um meio, legitimação pela moda 130

6.1.9. Resgate da noção de família, proteção e “concha” 133

6.1.10. Busca de referenciais do homem: antiguidade, história e memória. 137

6.1.11. Necessidade do design como símbolo: fechamento 141

6.2. Bloco II: A ponte 144

6.2.1. Principais objetos e seus significados 147 
7. Conclusão

8. Referências bibliográficas

165

9. Apêndices

173

10. Anexos

178

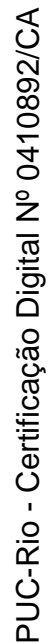




\section{Lista de figuras}

Figura 1 - Sala Cliente $01 \quad 15$

$\begin{array}{lr}\text { Figura } 2 \text { - Sala Cliente } 02 & 15\end{array}$

Figura 3 - Sala com descrição de elementos 30

Figura 4 - Tela de projetação em Autocad $\quad 44$

Figura 5 - Quadro Entrevistado $\quad 55$

Figura 6 - Quadro Entrevistado $\quad 55$

Figura 7 - Sala (Casa Claudia junho de 1973) 71

Figura 8 - Algumas salas (2 p., Casa Claudia - junho de 1973) 74

Figura 9 - Sala (2.p., Casa Claudia - janeiro de 1984

Figura 10 - Publicidade (1 p., Casa Claudia - janeiro de 1982) 77

Figura 11 - Capa (Casa Claudia - março de 1984) 79

Figura 12 - Feira de Milão (2 p., Casa Claudia $\quad$ - abril de 1982) 79

Figura 13 - Publicidade (1 p., Casa Claudia - setembro de 1985) 79

Figura 14 - Feira de Milão (Casa Claudia - dezembro de 1986) 80

Figura 15 - Feira de Milão 93 / revistas Casa Claudia 83

Figura 16 - Feira de Nova Iorque 83

(Casa Claudia - setembro de 1986)

Figura 17 - Capa (Casa Claudia - fevereiro de 1997) 83

Figura 18 - Capa (Casa Claudia - fevereiro de 1997) 84

Figura 19 - Sala, Feng Shui (2 p., Casa Claudia - março de 2000) 86

Figura 20 - Detalhe Abajur (Casa Claudia) 86

Figura 21 - Capa (Casa Claudia - janeiro de 2004) 88

Figura 22 - Sala (Casa Claudia - maio de 2004) 88

Figura 23 - Tabela Geral de perfil dos leitores Abril 96

Figura 24 - Tabela Geral de Circulação $\quad 97$

Figura 25 - Roteiro para entrevistas $\quad 99$

Figura 26 - Sofá - Entrevistada $04 \quad 101$

Figura 27 - Mesa - Entrevistada $04 \quad 101$

Figura 28 - Estante - Entrevistada $15 \quad 106$

Figura 29 - Sofá - Entrevistada $16 \quad 107$

Figura 30 - Tapetes - Entrevistado $09 \quad 108$

$\begin{array}{ll}\text { Figura } 31 \text { - Pufe - Entrevistada } 07 & 108\end{array}$

Figura 32 - Sala - Entrevistada $11 \quad 111$

Figura 33 - Bicicleta - Entrevistada $15 \quad 114$

Figura 34 - Puxador - Entrevistada $15 \quad 114$

Figura 35 - Luminária e sanca - Entrevistada $07 \quad 115$

Figura 36 - Sala - Entrevistado $09 \quad 119$

Figura 37 - Sala - Entrevistada $15 \quad 124$

Figura 38 - Tatus - Entrevistada $12 \quad 126$

Figura 39 - Sofá - Entrevistada $10 \quad 127$

Figura 40 - Porta-retratos - Entrevistada $10 \quad 127$

$\begin{array}{ll}\text { Figura } 41 \text { - Estante - Entrevistada } 07 & 146\end{array}$

$\begin{array}{ll}\text { Figura } 42 \text { - Maleta - Entrevistada } 04 & 148\end{array}$ 
Figura 43 - Aparador - Entrevistada 17

Figura 44 - Cadeira - Entrevistado 09

Figura 45 - Cadeira - Entrevistada 14

153

Figura 46 - Quadro - Entrevistada 14

154

Figura 47 - Santa - Entrevistada 13

162

Figura 48 - Divinos - Entrevistado 01

162

Figura 49 - Peixes - Entrevistada 08 
"Vou construir meus impérios para neles morar.

Neles porei muitos montes, fontes, pássaros,

cidades sem automóveis - só jardins.

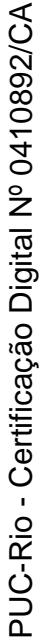

E uma casa singela e sombras de quintal.

Na varanda da casa, redes brancas."

(Antonio Brasileiro) 